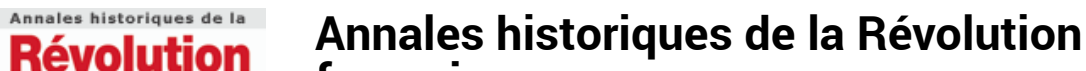

française française

338 | octobre-décembre 2004

Varia

\section{Mémoires et Souvenirs (1778-1841)}

Jean-Luc Chappey

\section{OpenEdition}

\section{Journals}

Édition électronique

URL : https://journals.openedition.org/ahrf/1870

DOI : 10.4000/ahrf.1870

ISSN : 1952-403X

Éditeur :

Armand Colin, Société des études robespierristes

Édition imprimée

Date de publication : 1 décembre 2004

Pagination : 183-184

ISSN : 0003-4436

Référence électronique

Jean-Luc Chappey, « Mémoires et Souvenirs (1778-1841) », Annales historiques de la Révolution

française [En ligne], 338 | octobre-décembre 2004, mis en ligne le 22 mars 2006, consulté le 23 avril

2022. URL : http://journals.openedition.org/ahrf/1870 ; DOI : https://doi.org/10.4000/ahrf.1870

Ce document a été généré automatiquement le 23 avril 2022.

Tous droits réservés 


\title{
Mémoires et Souvenirs (1778-1841)
}

\author{
Jean-Luc Chappey
}

\section{RÉFÉRENCE}

Augustin Pyramus de Candolle, Mémoires et Souvenirs (1778-1841), édité par Jean-Daniel Candaux et Jean-Marc Drouin, Genève, Georg Editeur, Bibliothèque d'histoire des sciences, 2003, 591 p., ISBN 2-8257-0832-1.

1 Voilà un ouvrage attendu dont la lecture contentera tous ceux qui s'intéressent à l'histoire sociale des sciences du premier dix-neuvième siècle. Fruit d'un travail de recherche mené pendant près de cinq années par Jean-Marc Drouin et Jean-Daniel Cadaux, deux spécialistes reconnus de l'histoire des sciences, la publication intégrale du manuscrit des Mémoires et souvenirs du naturaliste Augustin Pyramus de Candolle (Genève, 1778-idem, 1841) constitue un témoignage précieux sur les mutations de la vie scientifique qui caractérisent la période 1800-1830. Conforme aux règles du genre, cette autobiographie qui s'étend des premières années de l'enfance aux derniers mois avant la mort de l'auteur et mêle étroitement les souvenirs intimes aux réflexions les plus perspicaces, confère à l'itinéraire scientifique, mais aussi politique et social, de Candolle une épaisseur narrative qui en rend la lecture particulièrement stimulante. C'est sans doute en parvenant à faire jouer son double statut d'homme de science et d'écrivain que Candolle s'affirme, par cet ultime témoignage, comme l'une des grandes figures d'héritier des Lumières. De l'enfance à la vieillesse, le récit se décompose en cinq parties chronologiques qui sont autant d'étapes d'un voyage entre la Suisse, patrie de Candolle, et la France.

2 Après les premières années passées à Genève où se révèle sa vocation de botaniste dans une atmosphère familiale troublée par les événements révolutionnaires, Candolle «monte» à Paris en 1798 et se trouve rapidement plongé dans l'effervescence scientifique qui caractérise la capitale française sous le Directoire et le Consulat. Poursuivant ses études, il tissu ses réseaux de protections et d'amitiés (René Desfontaines, l'historien et diplomate portugais Jose-Francisco Correia de Serra, Jean- 
Baptiste Lamarck dont il réédite la Flore française), qui lui ouvrent les portes des espaces de sociabilité mondaine et intellectuelle (soulignons par exemple les informations qu'il nous donne sur la Société philomatique, la Société d'Arcueil ou la Société philanthropique de Paris). Quoiqu'il n'appartienne pas au groupe des acteurs consacrés et éminents de la vie scientifique, il parvient néanmoins à se tailler une réputation parmi le groupe des naturalistes, et plus précisément des botanistes, une réputation qui lui vaut de participer très activement aux débats sur les modalités de classification des plantes et de s'engager dans des travaux éditoriaux ambitieux. Ces activités foisonnantes et les stratégies qu'il déploie pour se gagner les soutiens politiques et scientifiques nécessaires lui permettent, en 1808, d'obtenir une place et de conforter sa position sociale. Nommé professeur de botanique à la Faculté de médecine de Montpellier, puis en 1809, directeur du Jardin botanique, il se voit désormais paré des atours du notable provincial, un statut qui, en dépit des multiples contraintes qu'il impose, ne l'empêche pas de mener, jusque dans les années 1814-1815, une activité pédagogique et scientifique débordante et novatrice. C'est en effet pendant cette période montpelliéraine qu'il s'impose comme l'un des acteurs essentiels de la " pensée classificatoire " et contribue à renouveler en profondeur certains des principes de la taxinomie végétale. Or, à une époque où les carrières scientifiques sont largement tributaires des événements politiques, la Restauration fait de Candolle une victime politique. Malgré les soutiens qu'il parvient à réunir, ce représentant du « juste milieu » et de la "modération » subit les assauts de l'offensive royaliste et catholique et doit, en 1815 , se résoudre à quitter la France pour se réfugier à Genève. Loin de se retrancher dans une paisible retraite, le retour de sa Patrie marque pour Candolle, qui s'impose alors comme l'une des personnalités helvétiques les plus influentes dans les domaines politiques et intellectuels, un nouveau départ. Poursuivant ses recherches en botanique et occupant des charges administratives importantes, son salon devient un passage obligé pour les élites scientifiques et politiques suisses et européennes. Ses voyages et les très nombreuses correspondances qu'il entretient, témoignent de son statut d'acteur et de témoin privilégié des mutations sociales, politiques et intellectuels qui caractérisent alors l'Europe.

On l'aura compris, cette autobiographie ne peut que susciter l'intérêt, voire l'enthousiasme du lecteur. Au-delà du regard lucide et non dénué d'une certaine ironie qu'il porte sur son existence, ce spécialiste de l'observation et de la description des plantes nous offre ici une tableau tout à fait passionnante des sociétés humaines et des jeux de pouvoir qui les traversent. Entre les galeries de portraits, parfois acerbes (n'oublions pas qu'une autobiographie sert aussi à régler des comptes et on se plaira à lire les jugements qu'il porte contre certains de ses rivaux et adversaires!) de personnages réputés et inconnus, les renseignements précieux qu'il nous offre sur les lieux et les espaces de la sociabilité mondaine, politique et intellectuelle de l'époque, les détails qu'il fournit sur les succès et les échecs de sa carrière ou sur les vicissitudes des entreprises éditoriales, nous sommes là face à une "source " historique de premier plan. On ne peut être que particulièrement intéressé par le récit qu'il donne par exemple des fameux "salons" parisiens ou provinciaux au sein desquels se recomposent progressivement les contours des élites sociales et politiques pendant le Consulat et l'Empire. C'est en effet parce que Candolle cherche à révéler les différentes logiques (sociales, politiques ou religieuses) qui se croisent autour de son itinéraire scientifique que son autobiographie constitue un document dont l'originalité, comme la qualité, méritent d'être soulignées. Plus encore, ce récit se présente comme un 
véritable journal scientifique à travers lequel se dévoile la construction progressive d'une théorie taxinomiste dont Jean-Marc Drouin, dans une introduction très éclairante, souligne la singularité épistémologique et méthodologique. À travers l'itinéraire de Candolle, c'est en effet un pan essentiel de l'histoire des sciences naturelles qui se dévoile : entre les pratiques d'un savant au travail et les modalités de la construction du savoir naturaliste qui sont finement décrites, c'est le fil expérimental d'une pensée en construction qui se révèle. Enrichie d'un appareil critique (bibliographie, notes, index et liste des publications) qui ne fait qu'enrichir l'intérêt du récit, cette autobiographie constitue un matériau déjà incontournable pour renouveler notre connaissance de l'histoire des sciences du premier dix-neuvième siècle. 